\title{
Study of the effects of ß-myrcene on rat fertility and general reproductive performance
}

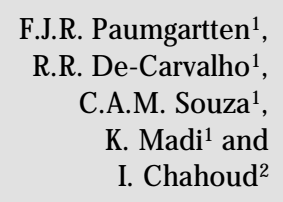

\author{
'Laboratório de Toxicologia Ambiental, Escola Nacional de Saúde Pública, \\ FIO CRUZ, Rio de Janeiro, RJ, Brasil \\ ${ }^{2}$ Institut fuer Toxikologie und Embryopharmakologie, Freie U niversitaet Berlin, \\ Berlin, Germany
}

\section{Correspondence \\ F.J.R. Paumgartten \\ Laboratório de Toxicologia \\ Ambiental, ENSP, FIOCRUZ \\ Av. Brasil, 4365 \\ 21045-900 Rio de Janeiro, RJ \\ Brasil \\ Research supported by $\mathrm{CNPq}$ and PAPES-FIO CRUZ. F.J.R. Paumgartten is the recipient of a CNPq fellowship.}

Received December 2, 1997 Accepted April 22, 1998

\section{Abstract}

B-Myrcene (MYR) is a monoterpene found in the oils of a variety of aromatic plants including lemongrass, verbena, hop, bay, and others. MYR and essential oils containing this terpenoid compound are used in cosmetics, household products, and as flavoring food additives. This study was undertaken to investigate the effects of MYR on fertility and general reproductive performance in the rat. $\operatorname{MYR}(0,100$, 300 and $500 \mathrm{mg} / \mathrm{kg}$ ) in peanut oil was given by gavage to male Wistar rats (15 per dose group) for 91 days prior to mating and during the mating period, as well as to females (45 per dose group) continuously for 21 days before mating, during mating and pregnancy, and throughout the period of lactation up to postnatal day 21. On day 21 of pregnancy one-third of the females of each group were submitted to cesarean section. Resorption, implantation, as well as dead and live fetuses were counted. All fetuses were examined for external malformations, weighed, and cleared and stained with Alizarin Red S for skeleton evaluation. The remaining dams were allowed to give birth to their offspring. The progeny was examined at birth and subsequently up to postnatal day 21. Mortality, weight gain and physical signs of postnatal development were evaluated. Except for an increase in liver and kidney weights, no other sign of toxicity was noted in male and female rats exposed to MYR. MYR did not affect the mating index (proportion of females impregnated by males) or the pregnancy index (ratio of pregnant to sperm-positive females). No sign of maternal toxicity and no increase in externally visible malformations were observed at any dose level. Only at the highest dose tested $(500 \mathrm{mg} / \mathrm{kg})$ did MYR induce an increase in the resorption rate and a higher frequency of fetal skeleton anomalies. No adverse effect of MYR on postnatal weight gain was noted but days of appearance of primary coat, incisor eruption and eye opening were slightly delayed in the exposed offspring. On the basis of the data presented in this paper the no-observed-adverse-effect level (NOAEL) for toxic effects on fertility and general reproductive performance can be set at $300 \mathrm{mg}$ of $\beta$ myrcene/kg body weight by the oral route.
Key words - ß-Myrcene

- Monoterpenes

- Essential oils

- Reproductive toxicity

- Fertility

- Embryofetal toxicity

- Postnatal development 


\section{Introduction}

ß-Myrcene (7-methyl-3-methylene-1,6octadiene) (MYR) is an acyclic monoterpene found in a large variety of plants including lemongrass, verbena, hop, bay, and others $(1,2)$. $\beta$-Myrcene and essential oils containing this terpenoid compound are widely used as a fragrance in cosmetics, as a scent in household products, and as a flavoring additive in food and alcoholic beverages (3). Furthermore, it was reported that $B$ myrcene is an analgesic substance and the active principle of lemongrass (Cymbopogon citratus Stapf) 'abafado', an infusion made with the pan covered in order to prevent the loss of volatile constituents (4). Lemongrass 'abafado' is widely used in Brazilian folk medicine as a sedative and as a remedy for gastrointestinal disorders (5).

The importance of human exposure to Bmyrcene, the widespread use of plants as well as essential oils containing large amounts of this monoterpene (e.g. lemongrass oil), and the relative paucity of data about its health risks prompted us to perform a rather comprehensive study of its reproductive toxicity.

The metabolism of $\beta$-myrcene was studied in the rabbit (6) and in the rat (7), and has been shown to induce liver monooxygenases $(8,9)$. The acute toxicity of $\beta$-myrcene was reported to be low (10) and this monoterpene was shown to have no genotoxic activity in vitro (11) or in vivo (12). No evidence that $\beta$-myrcene is a teratogenic substance was found (13) and the no-observed-adverse-effect level (NOAEL) for peri- and postnatal developmental toxicity in the rat was set at $0.25 \mathrm{~g} \beta$-myrcene $/ \mathrm{kg}$ body weight (14).

The aim of the present study was to investigate the effects of $\beta$-myrcene on rat fertility and general reproductive performance. This is segment I study, part of a more comprehensive evaluation of the reproductive toxicity of $\beta$-myrcene designed in three segments as recommended by the guidelines of the Food and Drug Administration, and of the Organization for Economic Cooperation and Development (OECD).

\section{Material and Methods}

\section{Animals}

Male and female Wistar rats (Bor: spf, TNO; Fa. Winkelmann, Borchen, Germany) were kept under $s p f$ conditions at a constant 12-h light-dark cycle (lights on from 9:00 to $21: 00 \mathrm{~h}$ ), at a room temperature of $21 \pm 1^{\circ} \mathrm{C}$ and $50 \pm 5 \%$ relative humidity. The animals received a standard pelleted diet (Altromin 1324, Lage, Germany) and tap water ad libitum during the experiment. All rats were adapted to the conditions of our animal quarters for three weeks before starting the experiment.

\section{Mating procedure}

Males were housed individually in a Macrolon type 3 cage with wood shavings as bedding. Three virgin females were placed inside the cage of one male for $2 \mathrm{~h}$ each day (7:00 to 9:00 h) and vaginal smears were evaluated for sperm. The first 24-h period following the mating procedure was called day 0 of pregnancy if sperm were detected in the smear. The mating procedure was repeated every working day until all three females became "sperm-positive" or, alternatively, for fifteen mating sessions extending over three weeks.

\section{Treatment}

Commercially available $\beta$-myrcene (Sigma Chemical Co., St. Louis, MO) was purified up to $95 \%$ (methanol extraction and HPLC purification) at our laboratory and administered to rats once a day during the following periods: a) male rats for 91 days prior to mating and during the mating period; b) female rats for 21 days prior to mating, 
during the mating period, and during pregnancy and lactation until day 21 after parturition.

Three experimental groups ( 15 males and 45 females per group) were treated by gavage with $\beta$-myrcene $(100,300$ and $500 \mathrm{mg} /$ $\mathrm{kg}$ body weight) dissolved in peanut oil (pharmaceutical grade). The control group received a similar treatment but with vehicle only (peanut oil, $2.5 \mathrm{ml} / \mathrm{kg}$ body weight).

\section{Evaluation of the animals}

All $\mathrm{F}_{\mathrm{o}}$-males and -females were evaluated for weight development, mortality, and signs of toxicity. Pregnant females were also observed for weight gain, signs of abortion, dystocia and prolonged duration of pregnancy. All males were sacrificed by decapitation and autopsied at the end of the mating period. All major organs were inspected macroscopically and weighed. Livers and one of the two testes were fixed in a $10 \%$ neutral buffered formalin solution for routine histological processing and light microscopic evaluation of sections stained with hematoxylin-eosin. The number of spermatozoa in the remaining testis and cauda epididymis was counted as described elsewhere (15). The following indices were used: mating index $=[$ No. of sperm-positive females : No. of mated females] x 100; pregnancy index $=[$ No. of pregnant females $\div$ No. of sperm-positive females] x 100 .

\section{Cesarean section}

On day 21 of pregnancy one-third of the females in each group were anesthetized by ethyl ether inhalation and killed by decapitation. The gravid uterus was weighed with its contents. Resorption as well as living and dead fetuses were counted. The number of implantation sites was determined by the method of Salewski (16). All living fetuses were immediately weighed, numbered with a marker pen, examined for externally vis- ible malformations and fixed in a 5\% formalin solution. All fetuses were examined for skeletal anomalies after clearing with potassium hydroxide and staining with Alizarin Red S (17).

\section{Postnatal development of the offspring}

All the remaining pregnant females were allowed to give birth to their offspring. From pregnancy day 20 on the dam's cages were inspected for births and the day of birth was designated as postnatal day 1 . As soon as possible after birth the numbers of viable and dead newborns were recorded, and the pups were sexed and weighed. Any newborn death on postnatal day 1 was considered to be a stillbirth. The weight gain of the pups was recorded on postnatal days $6,11,16$ and 21. Each pup was examined for signs of physical development and the days on which developmental landmarks appeared were recorded as follows: a) incisor eruption: the first sign of eruption through the gums of both lower incisors; b) fur development: the first detection of downy hair; c) eye opening: total separation of the upper and lower eyelids and complete opening of both eyes.

At weaning (postnatal day 21) all mothers were anesthetized with ethyl ether, killed by decapitation and subjected to postmortem examination.

\section{Statistical analysis}

Data were analyzed by one-way analysis of variance or, alternatively, by the KruskalWallis test whenever the data did not fit a normal distribution. Differences between groups were tested by the two-tailed Student $t$-test or Mann-Whitney U-test. Proportions were analyzed by the chi-square test or, alternatively, by the Fischer exact test. Statistical evaluation was performed using a MINITAB program (MTB, University of Pennsylvania, 1984), and a difference was considered statistically significant at $\mathrm{P}<0.05$. 


\section{Results}

\section{Body weight changes and toxicity to the parental generation}

No deaths were induced and no other signs of toxicity were apparent in male rats treated orally with B-myrcene $(100,300$ and $500 \mathrm{mg} / \mathrm{kg}$ body weight) for 91 days prior to mating and during the mating period. There were no statistically significant differences in body weight gain between the control and the MYR-treated male rats (Table 1). Except for a slight increase in both absolute and relative weights of liver and kidneys of males exposed to the highest dose tested (Table 1), no other treatment-related abnormality was noted in MYR-treated rats at autopsy. Light microscopy evaluation of sections stained with hematoxylin and eosin revealed no morphological alterations in the liver or testicular tissue of male rats exposed to $\beta$ myrcene. Moreover, no effect of MYR treat- ment was found either on the number of spermatids in the testis or on the number of spermatozoa in the cauda epididymis (data not shown).

Similarly, no adverse effects on body weight gain and no other signs of toxicity were observed in MYR-treated female rats during the premating (21 days) and mating periods.

\section{O utcome of fertility tests}

ß-Myrcene did not present any adverse effect on fertility indices at the dose range tested. As can be seen in Table 2, the proportion of females impregnated by male rats (mating index), and the ratio of pregnant to sperm-positive females (pregnancy index) did not differ between control and MYRtreated groups. Thus, no indication was found that MYR administered orally at doses as high as $500 \mathrm{mg} / \mathrm{kg}$ could impair male or female fertility.

Table 1 - Body weight gain and organ weight changes in male rats treated orally with ß-myrcene $(0,100,300$ and $500 \mathrm{mg} / \mathrm{kg}$ body weight) for 91 days prior to mating.

Values are reported as means $\pm \mathrm{SD}$. Data were analyzed by ANOVA and the Student t-test. $* \mathrm{P}<0.05$ compared to controls.

\begin{tabular}{lcccc}
\hline & \multicolumn{4}{c}{ B-Myrcene (mg/kg body weight) } \\
\cline { 2 - 5 } & 0 & 100 & 300 & 500 \\
\hline Body weight (g) & $434 \pm 26$ & $451 \pm 32$ & $428 \pm 24$ & $413 \pm 28$ \\
Body weight gain (g) & & & \\
$\quad$ (day 1-91) & $23 \pm 11$ & $27 \pm 15$ & $20 \pm 12$ & $16 \pm 19$ \\
Organ weight (g) & & & & \\
$\quad$ Liver & $13.3 \pm 1.7$ & $14.3 \pm 2.0$ & $14.1 \pm 1.6$ & $15.0 \pm 1.3^{*}$ \\
Kidneys & & & & \\
$\quad$ right & $1.25 \pm 0.11$ & $1.28 \pm 0.10$ & $1.28 \pm 0.12$ & $1.38 \pm 0.11^{*}$ \\
$\quad$ left & $1.25 \pm 0.12$ & $1.27 \pm 0.07$ & $1.30 \pm 0.11$ & $1.38 \pm 0.10^{*}$ \\
$\quad$ Spleen & $0.66 \pm 0.08$ & $0.66 \pm 0.07$ & $0.63 \pm 0.08$ & $0.63 \pm 0.10$ \\
Heart & $1.27 \pm 0.13$ & $1.34 \pm 0.06$ & $1.22 \pm 0.12$ & $1.18 \pm 0.10$ \\
$\quad \begin{array}{l}\text { Thymus } \\
\text { Brain }\end{array}$ & $0.21 \pm 0.05$ & $0.19 \pm 0.06$ & $0.17 \pm 0.04$ & $0.19 \pm 0.05$ \\
$\quad \begin{array}{l}\text { Testes } \\
\quad \text { right }\end{array}$ & $1.94 \pm 0.10$ & $1.96 \pm 0.12$ & $1.85 \pm 0.34$ & $1.70 \pm 0.21$ \\
$\quad$ left & $1.77 \pm 0.41$ & $1.75 \pm 0.21$ & $1.85 \pm 0.34$ & $1.66 \pm 0.22$ \\
$\quad$ & $1.80 \pm 0.39$ & $1.85 \pm 0.18$ & $1.83 \pm 0.16$ & $1.68 \pm 0.12$
\end{tabular}




\section{Evaluation of embryo-fetotoxic effects}

No adverse effect of MYR on pregnancy weight gain was noted at any dose level (Table 3). Except for a slight increase in the weights of liver and kidneys in the MYRtreated females, no other sign of toxicity to the maternal organism was observed. The body weight of MYR-treated fetuses did not differ from that of the control group at any dose level (Table 3). However, at the highest dose tested $(500 \mathrm{mg} / \mathrm{kg})$, MYR produced a slight increase in the resorption rate and a parallel decrease in the ratio of live fetuses per implantation site (Table 3 ).

The effects of prenatal exposure to MYR on the occurrence of fetal skeleton abnormalities are shown in Table 4. No differences between control and treated groups were observed at doses up to $300 \mathrm{mg}$ of MYR per kg body weight, but the frequency of skeletal malformations was increased at $500 \mathrm{mg} / \mathrm{kg}$. Nonetheless, the higher incidence of skeletal abnormalities observed at this dose level seems to have been due, to a
Table 2 - Outcome of fertility tests in rats continuously exposed to $ß$-myrcene $(0,100,300$ and $500 \mathrm{mg} / \mathrm{kg})$ during the premating period.

Mating index $=[($ No. of sperm-positive females $) \div($ No. of mated females) $] \times 100$; Pregnancy index $=$ [(No. of pregnant females) $\div$ (No. of sperm-positive females)] x 100 . There were no statistical differences between treated and untreated rats (chi-square test).

\begin{tabular}{lcccc}
\hline \multirow{2}{*}{ Outcome } & \multicolumn{4}{c}{ B-Myrcene (mg/kg body weight) } \\
\cline { 2 - 5 } & 0 & 100 & 300 & 500 \\
\hline Mated females (No.) & 45 & 45 & 45 & 45 \\
Mated males (No.) & 15 & 15 & 15 & 15 \\
Sperm-positive females (No.) & 44 & 39 & 37 & 41 \\
Pregnant females (No.) & 33 & 29 & 29 & 32 \\
Mating index (\%) & 98 & 87 & 82 & 91 \\
Pregnancy index (\%) & 75 & 74 & 78 & 78
\end{tabular}

large extent, to an increase in the occurrence of anomalies such as fused os zygomatic, dislocated sternum (non-aligned sternebrae) and lumbar extra ribs, the spontaneous frequencies of which are high in our rat strain. Anyhow, the higher incidence of skeletal abnormalities as well as the embryolethal effect clearly indicated that a dose as high as $500 \mathrm{mg} \mathrm{MYR} / \mathrm{kg}$ is embryotoxic to rats.

Table 3 - Effects of ß-myrcene $(0,100,300$ and $500 \mathrm{mg} / \mathrm{kg}$ ) administered by gavage during the premating, mating and gestation periods on parameters evaluated at the time of cesarean section performed on pregnancy day 21 for fetal body weight.

Proportions were analyzed by the chi-square test. Live fetuses per litter, uterus weight, maternal weight gain and fetal body weight are reported as means $\pm S D$ and were analyzed by one-way analysis of variance. Mean litter weight was taken as the unit of analysis for fetal body weight.

\begin{tabular}{|c|c|c|c|c|}
\hline & \multicolumn{4}{|c|}{ ß-Myrcene (mg/kg body weight) } \\
\hline & 0 & 100 & 300 & 500 \\
\hline Gravid uterus weight (g) & $67.0 \pm 10.2$ & $61.6 \pm 9.8$ & $71.0 \pm 16.8$ & $63.4 \pm 12.7$ \\
\hline \multicolumn{5}{|l|}{ Maternal weight gain (g) } \\
\hline$\Delta$ (day $0-21)$ & $79.0 \pm 11.8$ & $75.6 \pm 11.4$ & $84.3 \pm 11.8$ & $74.5 \pm 19.4$ \\
\hline$\Delta$ (day 0-21) - (uterine weight) & $12.0 \pm 14.6$ & $13.9 \pm 9.8$ & $13.3 \pm 12.1$ & $11.1 \pm 15.8$ \\
\hline Litters (No.) & 12 & 12 & 10 & 10 \\
\hline Implantation sites (No.) & 131 & 121 & 120 & 114 \\
\hline Resorptions (No.) & 4 & 5 & 4 & 12 \\
\hline Resorptions/implantations (\%) & 3.0 & 4.1 & 3.3 & $10.5^{*}$ \\
\hline Live fetuses (No.) & 127 & 116 & 116 & 102 \\
\hline Live fetuses/implantations (\%) & 97.0 & 95.9 & 96.7 & $89.5^{*}$ \\
\hline Live fetuses per litter & $10.6 \pm 2.1$ & $9.7 \pm 1.8$ & $11.6 \pm 3.0$ & $10.2 \pm 2.4$ \\
\hline Fetal body weight (g) & $4.42 \pm 0.43$ & $4.51 \pm 0.71$ & $4.36 \pm 0.46$ & $4.25 \pm 0.49$ \\
\hline
\end{tabular}




\section{Perinatal toxicity and postnatal development of the exposed offspring}

As shown in Table 5, duration of pregnancy was not affected by treatment with MYR at any dose level. No adverse effect of MYR on labor was noted in this experiment, and pup mortality in the treated groups was not above that observed in the vehicle-control group on the first day of life (stillbirths) or throughout lactation, i.e. from postnatal day 2 through day 21 (Table 5). Furthermore, no differences between control and MYR-treated groups were found with regard to maternal or offspring weight changes during the lactation period (Tables 5 and 6). In spite of the absence of MYR-induced effects on offspring body weight development, exposure to this monoterpene seemed to have caused a slight retardation in the appearance

Table 4 - Occurrence of skeletal abnormalities in fetuses from dams treated orally with Bmyrcene $(0,100,300$ and $500 \mathrm{mg} / \mathrm{kg})$ during the premating, mating and pregnancy periods.

$* \mathrm{P}<0.05$ compared to controls (chi-square test). Abbreviations: o.c. not ossified $=$ ossification centre not ossified; incpl. ossif. = incomplete ossification; irreg. ossif. = irregular ossification; dumbbell $=$ dumbbell shaped; bicent. $=$ bicentric; part. $=$ partial; sym. $=$ symmetrical .

\begin{tabular}{|c|c|c|c|c|}
\hline & \multicolumn{4}{|c|}{ ß-Myrcene (mg/kg body weight) } \\
\hline & 0 & 100 & 300 & 500 \\
\hline Fetuses examined (No.) & 127 & 116 & 116 & 102 \\
\hline Fetuses with skeleton abnormalities (\%) & 35.4 & 27.5 & 35.3 & $64.7^{*}$ \\
\hline \multicolumn{5}{|l|}{ Fetuses with anomalies in (\%) } \\
\hline Forelimbs & 2.36 & 8.62 & 2.58 & 1.96 \\
\hline finger (o.c. not ossif.) & 2.36 & 7.75 & 1.72 & 0.98 \\
\hline humerus (bent) & 0 & 0 & 0 & 0.98 \\
\hline Skull & 9.44 & 11.2 & 12.0 & 15.6 \\
\hline os interparietalis (incpl. ossif.) & 3.93 & 1.72 & 5.17 & 4.90 \\
\hline os parietalis (incpl. ossif.) & 2.36 & 1.72 & 0.86 & 1.96 \\
\hline os supraoccipitalis (irreg. ossif.) & 0.78 & 0 & 0 & 0 \\
\hline (incpl. ossif.) & 0 & 0 & 1.72 & 0 \\
\hline os zygomatic (fused) & 5.51 & 1.72 & 6.03 & 8.82 \\
\hline p.j. os maxill. (incpl. ossif.) & 0.78 & 0 & 0 & 0 \\
\hline (bone hole) & 0 & 0 & 0 & 1.96 \\
\hline Sternum & 10.2 & 6.89 & 6.03 & 16.6 \\
\hline (bent) & 2.36 & 0 & 0 & 2.94 \\
\hline (dislocated) & 3.14 & 5.17 & 3.44 & 9.80 \\
\hline ossif. centre $1 / 2$ (fused) & 0.78 & 0 & 0.86 & 0.98 \\
\hline ossif. centre 2 (irreg. shaped) & 0 & 0 & 0.86 & 0.98 \\
\hline ossif. centre 2 (narrow) & 0 & 0 & 0 & 0.98 \\
\hline ossif. centre 5 (additional) & 3.14 & 0 & 0 & 0.98 \\
\hline ossif. centre 5 (incpl. ossif.) & 0.78 & 0 & 0 & 0 \\
\hline ossif. centre 5 (narrow) & 0 & 0 & 0 & 1.96 \\
\hline ossif. centre 5 /6 (additional) & 0 & 1.72 & 0.86 & 0 \\
\hline Thorax & 15.7 & 6.03 & 13.7 & 21.5 \\
\hline Ribs (extra lumbar) & 12.5 & 4.31 & 12.9 & 19.6 \\
\hline (wavy) & 3.14 & 1.72 & 0.86 & 3.92 \\
\hline Vertebral column & 8.66 & 5.17 & 10.3 & 27.4 \\
\hline (bent) & 0 & 3.44 & 0.86 & 13.7 \\
\hline Lumbar vertebra (additional) & 0 & 0.86 & 0 & 0.98 \\
\hline \multicolumn{5}{|l|}{ Thoracic vertebra } \\
\hline (o.c. bicent., part.) & 3.93 & 4.31 & 7.75 & 9.80 \\
\hline (o.c. bicent., sym.) & 0.78 & 0 & 1.72 & 0.98 \\
\hline (o.c. dumbbell) & 1.57 & 0.86 & 0 & 2.94 \\
\hline
\end{tabular}


Table 5 - Duration of pregnancy, number of stillbirths, postnatal mortality and weight gain of offspring of rats treated orally with ß-myrcene $(0,100,300$ and $500 \mathrm{mg} / \mathrm{kg}$ body weight) during pregnancy and lactation.

Data were analyzed by the chi-square test (proportions), Kruskal-Wallis (duration of pregnancy) and ANOVA (body weight and litter size). \% of stillbirths $=$ [No. of stillbirths/total of pups born] $\times 100 ; \%$ of pups dead $=$ [No. of pups dead/No. of viable pups on day 1$] \times 100$. $* \mathrm{P}<0.05$ compared to control group.

\begin{tabular}{|c|c|c|c|c|}
\hline \multirow[b]{3}{*}{ Duration of pregnancy (days) } & \multicolumn{4}{|c|}{ ß-Myrcene (mg/kg body weight) } \\
\hline & \multirow{2}{*}{$\begin{array}{c}0 \\
23.0 \pm 0.5\end{array}$} & 100 & \multirow{2}{*}{$\frac{300}{23.0 \pm 0.4}$} & 500 \\
\hline & & $23.1 \pm 0.5$ & & $23.0 \pm 0.4$ \\
\hline Total of pups born & 173 & 146 & 176 & 174 \\
\hline Viable pups on day 1 & 161 & 133 & 174 & 159 \\
\hline Stillbirths (\%) & $12(6.9)$ & $13(8.9)$ & $2(1.1)^{*}$ & $15(8.6)$ \\
\hline Viable pups on day 21 & 143 & 122 & 166 & 132 \\
\hline \multicolumn{4}{|l|}{ Pups dead between postnatal } & $27(17.0)$ \\
\hline \multicolumn{5}{|l|}{$\begin{array}{l}\text { Postnatal weight gain }(g) \\
\text { day } 1\end{array}$} \\
\hline body weight & $6.0 \pm 0.9$ & $5.5 \pm 0.8$ & $5.3 \pm 0.6$ & $5.4 \pm 0.7$ \\
\hline litter size & $8.1 \pm 2.4$ & $8.3 \pm 4.3$ & $9.2 \pm 3.0$ & $8.0 \pm 2.9$ \\
\hline \multicolumn{5}{|l|}{ day 7} \\
\hline body weight & $11.9 \pm 2.0$ & $10.6 \pm 2.3$ & $10.7 \pm 1.5$ & $10.3 \pm 1.9$ \\
\hline litter size & $7.5 \pm 2.7$ & $8.1 \pm 4.3$ & $8.8 \pm 3.0$ & $7.4 \pm 2.8$ \\
\hline \multicolumn{5}{|l|}{ day 14} \\
\hline body weight & $22.0 \pm 3.9$ & $20.0 \pm 4.4$ & $20.0 \pm 4.4$ & $20.0 \pm 4.0$ \\
\hline litter size & $7.5 \pm 2.7$ & $8.1 \pm 3.6$ & $8.7 \pm 3.0$ & $7.4 \pm 2.8$ \\
\hline \multicolumn{5}{|l|}{ day 21} \\
\hline body weight & $34.0 \pm 7.2$ & $31.0 \pm 11.0$ & $31.0 \pm 6.6$ & $32.0 \pm 11.0$ \\
\hline litter size & $7.5 \pm 2.7$ & $8.1 \pm 3.6$ & $8.7 \pm 3.0$ & $7.4 \pm 2.8$ \\
\hline
\end{tabular}

Table 6 - Weight development of female rats treated orally with ß-myrcene $(0,100,300$ and $500 \mathrm{mg} / \mathrm{kg}$ body weight) during pregnancy and lactation.

Values are reported as means \pm SD. Data were analyzed by ANOVA and the Student t-test and no significant differences were detected. Dams submitted to cesarean section on pregnancy day 21 were not included. Days of pregnancy and days of lactation are indicated by subscripts $P$ and $L$, respectively.

\begin{tabular}{|c|c|c|c|c|}
\hline & \multicolumn{4}{|c|}{ ß-Myrcene (mg/kg body weight) } \\
\hline & 0 & 100 & 300 & 500 \\
\hline No. & 21 & 17 & 19 & 22 \\
\hline \multicolumn{5}{|c|}{ Days of pregnancy and lactation period } \\
\hline $1_{\mathrm{p}}$ & $220 \pm 10$ & $222 \pm 10$ & $223 \pm 13$ & $224 \pm 12$ \\
\hline $6 p$ & $234 \pm 10$ & $237 \pm 10$ & $239 \pm 13$ & $234 \pm 15$ \\
\hline 10p & $246 \pm 22$ & $243 \pm 11$ & $250 \pm 14$ & $246 \pm 14$ \\
\hline $15 p$ & $261 \pm 15$ & $259 \pm 11$ & $268 \pm 17$ & $257 \pm 14$ \\
\hline $21_{p}$ & $304 \pm 15$ & $298 \pm 16$ & $307 \pm 17$ & $288 \pm 21$ \\
\hline $1_{L}$ & $225 \pm 20$ & $224 \pm 12$ & $224 \pm 18$ & $219 \pm 17$ \\
\hline $7 \mathrm{~L}$ & $244 \pm 17$ & $241 \pm 11$ & $249 \pm 18$ & $239 \pm 20$ \\
\hline $14_{L}$ & $257 \pm 17$ & $254 \pm 16$ & $269 \pm 16$ & $253 \pm 20$ \\
\hline $21_{\mathrm{L}}$ & $260 \pm 14$ & $260 \pm 22$ & $271 \pm 16$ & $260 \pm 16$ \\
\hline \multicolumn{5}{|l|}{ Weight gain (g) } \\
\hline$\Delta\left(1_{P}-1_{L}\right)$ & $4.4 \pm 19$ & $-0.4 \pm 13$ & $-0.3 \pm 10$ & $4.0 \pm 17$ \\
\hline$\Delta\left(1_{L}-21_{L}\right)$ & $35 \pm 15$ & $37 \pm 26$ & $47 \pm 14$ & $38 \pm 12$ \\
\hline
\end{tabular}


of incisor eruption, primary coat and eye opening (Table 7). This effect was not doserelated and the MYR-induced delay was more evident with incisor eruption $(300 \mathrm{mg} / \mathrm{kg}$ ) and eye opening (100 and $300 \mathrm{mg} / \mathrm{kg}$ ). Except for this minor effect on physical maturation, no other indication was found that MYR at doses up to $500 \mathrm{mg} / \mathrm{kg}$ impaired the postnatal development of the treated offspring.

\section{Discussion}

Except for a slight increase in the absolute and relative weights of liver and kidneys, no other effects were noted in male rats continuously exposed to $\beta$-myrcene for 91 days prior to mating and during the mating period. Since B-myrcene has proved to be an inducer of hepatic monooxygenases (8), liver enlargement probably resulted from the marked hypertrophy of the endoplasmic reticulum due to the induction of microsomal enzyme synthesis in treated animals (18).

On the other hand, the mechanism underlying the $\beta$-myrcene-induced enlargement of kidneys is still far from being entirely under- stood. $\beta$-Myrcene was reported to cause a sex-specific hyaline droplet nephropathy in male rats very similar to that produced by $d$ limonene, a monocyclic monoterpene (19). $d$-Limonene-induced hyaline nephropathy was shown to be due to an epoxide metabolite ( $d$-limonene-1,2-oxide) that binds to an $\alpha_{2 \mu}$-globulin thereby preventing its lysosomal degradation and leading to an accumulation of this low molecular weight protein in the cytoplasm (hyaline droplets) of the proximal tubule cells (20). In the case of MYRinduced kidney damage the $\alpha_{2 \mu}$-globulin ligand is still unknown, but it should be noted that microsomal oxidation of MYR olefinic bonds seems to yield epoxide metabolites structurally similar to $d$-limonene 1,2-oxide (21). Anyhow, since the hyaline droplet nephropathy is sex-specific (i.e. female rats do not produce $\alpha_{2 \mu}$-globulin), and the increase in kidney weight was noted in both males and females, the renal enlargement cannot be attributed only to the accumulation of hyaline droplets. One possible explanation for the kidney enlargement would be an induction of renal microsomal enzyme synthesis by MYR and $d$-limonene.

Table 7 - Physical signs of postnatal development of offspring of rats treated orally with B-myrcene $(0,100$, 300 and $500 \mathrm{mg} / \mathrm{kg}$ body weight).

$* \mathrm{P}<0.05$ compared to controls (chi-square test).

\begin{tabular}{|c|c|c|c|c|c|c|c|c|c|c|c|c|}
\hline \multirow[t]{2}{*}{ Postnatal day } & \multicolumn{4}{|c|}{ Primary coat (\%) } & \multicolumn{4}{|c|}{ Incisor eruption (\%) } & \multicolumn{4}{|c|}{ Eye opening (\%) } \\
\hline & 0 & 100 & 300 & 500 & 0 & 100 & 300 & 500 & 0 & 100 & 300 & 500 \\
\hline 7 & 78 & $67^{*}$ & $48^{*}$ & $59^{*}$ & 1.4 & - & - & - & - & - & - & - \\
\hline 8 & 99 & 94 & 95 & 90 & 2.8 & 38 & 4.2 & 1.5 & - & - & - & - \\
\hline 9 & 100 & 100 & 100 & 97 & 41 & 79 & $27^{*}$ & $33^{*}$ & - & - & - & - \\
\hline 10 & - & - & - & 100 & 78 & 99 & $57^{*}$ & 81 & - & - & - & - \\
\hline 11 & - & - & - & - & 98 & 100 & $87^{*}$ & 100 & - & - & - & - \\
\hline 12 & - & - & - & - & 100 & - & 98 & - & - & - & - & - \\
\hline 13 & - & - & - & - & - & - & 100 & - & 3.5 & 4.1 & 0.6 & 3 \\
\hline 14 & - & - & - & - & - & - & - & - & 26 & 12 & 5.4 & 40 \\
\hline 15 & - & - & - & - & - & - & - & - & 68 & $43^{*}$ & $37^{*}$ & $50^{*}$ \\
\hline 16 & - & - & - & - & - & - & - & - & 93 & $73^{*}$ & $73^{*}$ & 87 \\
\hline 17 & - & - & - & - & - & - & - & - & 100 & $83^{*}$ & 100 & 99 \\
\hline 18 & - & - & - & - & - & - & - & - & - & 98 & - & 100 \\
\hline 19 & - & - & - & - & - & - & - & - & - & 100 & - & - \\
\hline
\end{tabular}


Data from the present study suggest that continuous exposure of male rats to $\beta$ myrcene for 91 days prior to mating and during the mating period did not cause any histological changes in the testis and did not impair male fertility. Since $\beta$-myrcene is a highly lipophilic substance that reaches a rather high concentration in the testes (Webb J, Chahoud I and Paumgartten FJR, unpublished results), it seems unlikely that the absence of adverse effects on male fertility is due to an insufficient exposure of male germ cells to this monoterpene. The results also suggest that female fertility was not affected by continuous exposure to $ß$-myrcene for 21 days prior to mating and during the mating period. The percentages of MYR-treated females that copulated (mating index) and were impregnated by males (pregnancy index) did not differ from those obtained for the vehicle-control group at any dose level. In addition, MYR had no detectable effect on the frequency of pre-implantation losses since no difference in the number of implantation sites per dam was found when treated animals were compared to the controls. Thus, apparently no adverse effect on reproductive function was caused by MYR from gametogenesis up to implantation of the blastocyst in the maternal uterus.

Notwithstanding the absence of adverse effects on female fertility in the present study, MYR, at doses as high as 1.0 and $1.5 \mathrm{~g} / \mathrm{kg}$, was shown to impair female offspring fertility in a segment III-designed study in rats (14). It should be emphasized, however, that not only the doses, but also the periods of exposure to MYR were quite different in the two studies. While in the present experiment only adult females were treated with MYR, in the segment III study female offspring were exposed while still in utero, from pregnancy day 15 on and throughout lactation. Therefore, the absence of adverse effects on female fertility in the present study might have been due either to the lower dose levels tested, or to the different period of exposure, or to both. In any case, MYR-induced impairment of female fertility in the segment III study was apparent only at very high doses when a pronounced perinatal mortality occurred as well (14).

Except for liver and kidney enlargement, no indication of MYR-induced maternal effects was found at any dose level and no embryotoxic effects were detected at doses lower than $500 \mathrm{mg} / \mathrm{kg}$ body weight. On the other hand, a slight increase in the resorption rate and a higher incidence of skeletal abnormalities indicated that, in the present study, $500 \mathrm{mg}$ MYR $/ \mathrm{kg}$ was an embryotoxic dose. Absence of signs of maternal toxicity at 500 $\mathrm{mg}$ MYR $/ \mathrm{kg}$ was also found in segment II(13) as well as in segment III-designed studies in rats (14). Nonetheless, in the segment II study MYR-induced embryotoxic effects were observed only at a higher and maternally toxic dose (13). Since in the segment II study MYR was administered during the second week (pregnancy days 6 to 15) whereas in the present study treatment continued throughout pregnancy, the highest susceptibility of the embryos in the latter may have been due to a longer exposure to this monoterpene. It should also be pointed out that, in the present study, most of the skeletal abnormalities whose incidence was increased in MYR-treated animals were anomalies which occurred at a high frequency in the historical group as well as in the vehicle-control group. Under these circumstances, the toxicological significance of the fetal skeleton findings seems to be minor.

Parturition, perinatal pup mortality as well as postnatal weight gain of the exposed offspring during the lactation period were not affected by MYR at any of the doses tested. The only effect of MYR on postnatal development detected in the present study was a substance-produced delay on the day of appearance of some milestones of somatic maturation. No dose-response relationship was found and retardation was more evident at $300 \mathrm{mg} / \mathrm{kg}$ (incisor eruption and eye open- 
ing) and $300 \mathrm{mg} / \mathrm{kg}$ (eye opening) than at the highest dose tested $(500 \mathrm{mg} / \mathrm{kg})$. Since this slight effect was not related to the dose and was not accompanied by any other indication that postnatal development was impaired in the treated animals, it was not taken into account for setting the present study-derived NOAEL .

Contrasting with the absence of toxicity in the present experiment, an increased pup mortality on the first day of life and during the first week of lactation, as well as a reduced pup birth weight, were found after treatment with $500 \mathrm{mg} \mathrm{MYR} / \mathrm{kg}$ in the segment III study (14). A possible explanation for this discrepancy is the development of tolerance to the toxic effects of $\beta$-myrcene, since in the segment III study treatment began on pregnancy day 15 , whereas in the present study administration of this monoterpene to the females started 21 days before mating. The induction of liver microsomal enzymes by MYR ( 8 ) and the observed crosstolerance with pentobarbital effects (9) are findings that give additional support to this interpretation.

On the basis of the data presented in this paper the NOAEL for the toxic effects of $\beta$ myrcene on fertility and general reproductive performance can be set at $300 \mathrm{mg} / \mathrm{kg}$ body weight by the oral route. This dose is about the same NOAEL as found in a segment-III-designed study and approximately half the NOAEL obtained for MYR-induced embryotoxicity (segment II) in the rat. Although no quantitative data on human exposure to $\beta$-myrcene are available, it seems very unlikely that dose levels comparable to this experimentally derived NOAEL could be attained when humans are exposed to this olefinic monoterpene through the use of MYR-containing essential oils or folk medicine potions.

\section{References}

1. Günther E \& Althausen D (1949). ßmyrcene. In: Günther E (Editor), The Essential Oils. The Constituents of Essential Oils. Vol. II. D. Van Nostrand Co., New York, 8-10.

2. Simonsen JL \& Owen LN (1953). Myrcene. In: Simonsen J L (Editor), The Terpenes. The Simpler Acyclic and Monocyclic Terpenes and their Derivatives. Vol. I. 2nd edn. Cambridge University Press, Cambridge, 12-19.

3. Leung AY (1980). Encyclopedia of Common Natural Ingredients Used in Food, Drugs and Cosmetics. J ohn Wiley \& Sons, New York.

4. Lorenzetti BB, Souza GEP, Sarti SJ , Santos-Filho D \& Ferreira SH (1991). Myrcene mimics the peripheral analgesic activity of lemongrass tea. J ournal of Ethnopharmacology, 34: 43-48.

5. Carlini EA, Contar J DP, Silva-Filho AR, Silveira-Filho NG, Frochtengartten $M L$ \& Bueno OFA (1986). Pharmacology of lemongrass (Cymbopogon citratus Stapf.). I. Effects of teas prepared from the leaves on laboratory animals. J ournal of Ethnopharmacology, 17: 37-64.

6. Ishida T, Asakawa Y, Takemoto $T \&$ Aratani T (1981). Terpenoids biotransformation in mammals. III. Biotransformation of $\alpha$-pinene, $\beta$-pinene, pinane, 3 carene, carane, myrcene, and p-cymene in rabbits. J ournal of Pharmaceutical Sciences, 70: 406-415.

7. Madyastha KM \& Srivatsan V (1987). Metabolism of ß-myrcene in vivo and in vitro: its effects on rat liver microsomal enzymes. Xenobiotica, 17: 539-549.

8. De-Oliveira ACAX, Ribeiro-Pinto LF, Otto SS, Gonçalves A \& Paumgartten FJ R (1997). Induction of liver monooxygenases by ß-myrcene. Toxicology, 124: 135-140.

9. Freitas J CBR, Presgrave OAF, Fíngola FF, Menezes MAC \& Paumgartten FJ R (1993). Effect of ß-myrcene on pentobarbital sleeping time. Brazilian J ournal of Medical and Biological Research, 26: 519523.

10. Paumgartten FJ R, Delgado IF, Alves EN,
Nogueira ACMA, De-Farias RC \& Neubert $D$ (1990). Single dose toxicity study of $ß$ myrcene, a natural analgesic substance. Brazilian J ournal of Medical and Biological Research, 23: 873-877.

11. Kauderer B, Zamith H, Paumgartten FJ R \& Speit G (1991). Evaluation of the mutagenicity of ß-myrcene in mammalian cells in vitro. Environmental and Molecular Mutagenesis, 18: 28-34.

12. Zamith HPS, Vidal MNP, Speit G \& Paumgartten FJ R (1993). Absence of genotoxic activity of $ß$-myrcene in the in vivo cytogenetic bone marrow assay. Brazilian J ournal of Medical and Biological Research, 26: 93-98.

13. Delgado IF, Carvalho RR, Nogueira ACMA, Mattos AP, Figueiredo LH, Oliveira SHP, Chahoud I \& Paumgartten FJ R (1993). Study on the embryofoetotoxicity of ß-myrcene in the rat. Food and Chemical Toxicology, 31: 31-35.

14. Delgado IF, Nogueira ACMA, Souza CAM, Costa AMN, Figueiredo LH, Mattos AP, Chahoud I \& Paumgartten FJR (1993). 
Peri- and postnatal developmental toxicity of ß-myrcene in the rat. Food and Chemical Toxicology, 31: 623-628.

15. Dalsenter PR, Faqi AS, Webb J, Merker H-J \& Chahoud I (1997). Reproductive toxicity and toxicokinetics of lindane in the male offspring of rats exposed during lactation. Human and Experimental Toxicology, 16: 146-153.

16. Salewski E (1964). Färbemethoden zum makroskopischen Nachweis von Implantationsstellen am Uterus der Ratte. Naunyn-Schmiedeberg's Archiv für experimentelle Pathologie und Pharmakologie, 247: 367.
17. Dawson AB (1926). A note on the staining of the skeleton of cleared specimens with Alizarin Red S. Stain Technology, 1: 123124.

18. Miyai K (1979). Ultrastructural basis for liver injury. In: Farber E \& Fischer MM (Editors), Liver Normal Function and Disease. Part A: Toxic Injury of the Liver. Vol. I. Marcel Dekker Inc., New York, 59-154.

19. Paiva RO, Madi K, Araujo IB, Souza CAM, Kuriyama SN, Faccini A \& Paumgartten FJ R (1997). Beta-mirceno causa nefropatia tubular hialina em ratos machos. Proceedings of XII Reunião Anual da Federação das Sociedades de Biologia Ex- perimental, FESBE, 27-30 August 1997, Caxambu, MG, Brazil, 378 (Abstract).

20. Lehman-McKeeman LD, Rodriguez PA, Takigiku R, Caudill D \& Fey ML (1989). Dlimonene-induced male rat-specific nephrotoxicity: evaluation of the association between d-limonene and alpha $2 \mu$-globulin. Toxicology and Applied Pharmacology, 99: 250-259.

21. Hard GC \& Whysner J (1994). Risk assessment of d-limonene: An example of male rat-specific renal tumorigens. Critical Reviews in Toxicology, 24: 231-254. 